\title{
Effects of school climate and teacher self- efficacy on job satisfaction of mostly STEM teachers: a structural multigroup invariance approach
}

\author{
Yusuf F. Zakariya (D)
}

\begin{abstract}
Background: Identification and retention of effective teachers in STEM education play cardinal roles in teacher recruitment exercises worldwide. Studies on factors that characterize effective teachers have therefore gained popularity in recent times. Teacher self-efficacy, job satisfaction and school climate are among other factors that have attracted global attention. Thus, proper understanding of the relations between these factors is equally important. The purpose of this study is to validate and cross-validate a model of direct/indirect effects of school climate and teacher self-efficacy on job satisfaction.
\end{abstract}

Results: The data used for the current study are extracted from a publicly available data of Teaching and Learning International Survey (TALIS) 2018 survey. Structural equation modeling approach was used in the analyses coupled with robust maximum likelihood to ensure accurate estimations in the models. The results of the validated models show a strong direct impact of school climate on job satisfaction, a direct impact of teacher self-efficacy on job satisfaction and a mediating effect of teacher self-efficacy between school climate and job satisfaction. This model exhibits structural invariance in factor loadings, intercepts and regression weights across two independent samples from a population of 3951 lower secondary school teachers in Norway.

Conclusion: The findings of this study do provide empirical evidence for the relations between teacher selfefficacy, job satisfaction and school climate among Norwegian lower secondary school teachers. The crossvalidation of these relations was also established using an independent sample to enhance generalization of the findings. Two methodological observations concerning recoding of some items as well as an addition of item cross-loading in the measurement model of the job satisfaction scales are raised and addressed. It is therefore recommended that researchers who will be using TALIS 2018 data should take note of these observations.

Keywords: TALIS 2018, Teacher self-efficacy, School climate, Job satisfaction, Multigroup invariance

\section{Introduction}

Identification and retention of efficacious teachers have long been playing cardinal roles in teacher recruitment exercises worldwide. This occurrence can be linked to the pronounced role of teacher self-efficacy in improving quality of learning outcomes (e.g. Caprara, Barbaranelli,

Correspondence: yusuf.zakariya@uia.no

Department of Mathematical Sciences, University of Agder, Kristiansand, Norway
Steca, \& Malone, 2006). Globally, increased attention has been witnessed in recent times especially in the aspect of factors that enhance or inhibit self-efficacy of primary and secondary school teachers. For example, multiple results from the Organization for Economic Co-operation and Development (OECD) and Teaching and Learning International Survey (TALIS) 2013 and 2018 studies have shown that teacher perceived disciplinary (which is an aspect of school climate factor) has a

\section{Springer Open}

(c) The Author(s). 2020 Open Access This article is licensed under a Creative Commons Attribution 4.0 International License, which permits use, sharing, adaptation, distribution and reproduction in any medium or format, as long as you give appropriate credit to the original author(s) and the source, provide a link to the Creative Commons licence, and indicate if changes were made. The images or other third party material in this article are included in the article's Creative Commons licence, unless indicated otherwise in a credit line to the material. If material is not included in the article's Creative Commons licence and your intended use is not permitted by statutory regulation or exceeds the permitted use, you will need to obtain permission directly from the copyright holder. To view a copy of this licence, visit http://creativecommons.org/licenses/by/4.0/. 
negative correlation with teacher self-efficacy (OECD, 2014, 2019a). Further, teachers who had high scores on their job satisfaction scales are identified with high selfefficacy as well. Explorations of the relationships between these constructs-teacher self-efficacy, school climate and job satisfaction-have many implications for teachers' identification, retention and recruitment and by extension quality of learning outcomes.

Several attempts have been made to establish these relationships in the literature. However, the results are inconsistence or rather inconclusive. For instance, Caprara et al. (2006) in a study involving 2184 junior high school teachers reported a significant impact of teacher selfefficacy on their job satisfaction. Similar finding of a strong predictive power of teacher job satisfaction by teacher self-efficacy has also been reported in (Skaalvik \& Skaalvik, 2014; You, Kim, \& Lim, 2016). On the other hand, Blackburn and Robinson (2008) in their study involving 80 early career teachers found a significant positive correlation between 'teacher self-efficacy in student engagement' and job satisfaction, and a significant negative correlation between 'teacher self-efficacy in classroom management' and job satisfaction. Some aspects of the school climate such as teacher-student relations have also been reported to correlate positively with teacher self-efficacy (e.g. Hosford \& O'Sullivan, 2016). More recently, in contrary to the earlier findings Shaukat, Vishnumolakala, and Al Bustami (2019) reported no significant relationship between teacher self-efficacy and job satisfaction.

Several other researchers have adopted structural equation modeling approach to unravel the causal relationships between these constructs. An empirical longitudinal study on 642 teachers in lower secondary schools revealed that school climate exerts a positive impact on job satisfaction. However, this impact is mediated by teacher self-efficacy (Malinen \& Savolainen, 2016). This finding is consistent with a significant mediating effect of teacher self-efficacy between school climate and job satisfaction reported in (Aldridge \& Fraser, 2016). The main issue with most of these structural equation modeling approaches to testing hypothesized relationships between these constructs is lack of cross-validation. It is a common practice among researchers to test a structural model and improve on it to achieve model fits by conducting post hoc analyses without any recourse to further validations in independent samples (e.g. Aldridge \& Fraser, 2016). Meanwhile, the post hoc analysis procedure is purely exploratory since it involves adding or freeing constraints as suggested by the data and therefore limits generalization. A way of circumventing this problem is to conduct a cross-validation of a well fitted model through multigroup invariance. Another solution to this problem could also involve conducting longitudinal studies (Byrne, 2012).
This lack of cross-validation of the tested structural model on school climate, teacher self-efficacy and teacher job satisfaction coupled with inconclusive results on the relationships between these constructs have created knowledge gaps begging for more investigations. The current study is aimed at providing empirical evidence to fill these gaps within a national context and by extension to a global community. In specific terms, the current study seeks to provide empirical evidence for: (a) a structural model that explains the direct effect of school climate on job satisfaction, direct effect of teacher self-efficacy on job satisfaction and indirect effect of school climate on job satisfaction as mediated by the teacher self-efficacy; (b) cross-validation of this structural model using independent sample from the same population; (c) multigroup invariance testing of the estimated parameters and regression weights of the structural model. In the forthcoming section, a theoretical background coupled with conceptual propositions of this study are presented.

\section{Conceptual framework}

A theoretical model that could explain teacher job satisfaction and its associated teachers' personal traits, e.g. teacher self-efficacy and environmental factors, e.g. school climate, is the social ecological theory (Bronfenbrenner, 1986; Darling, 2007). This grand theory sees an actor (e.g. a teacher) as a person whose intrinsic feelings (e.g. job satisfaction, self-efficacy) are constantly being shaped by interaction with the environment (e.g. school climate). From this theoretical perspective, one can justify the rationality of establishing empirical relations between these constructs. However, in order to maintain consistency with the source of data used in the current study, subsequent discussions are based on the conceptual framework and technical report as released by the TALIS 2018 team (Ainley \& Carstens, 2018; OECD, $2019 b)$. TALIS is an international survey that is sponsored by the OECD to provide empirical evidence for the teaching and learning practices among teachers and school principals. It is cyclical survey that is conducted every 5 years and covers several aspects of teachers'/ principals' factors including instructional practices, job satisfaction, professional practices, self-efficacy, school climate, school leadership, teacher feedback and development. Thus, the current study relies on TALIS for its data source being the only large scale publicly available data on the research constructs under investigation.

\section{Teacher job satisfaction}

Teachers' intrinsic evaluations of their jobs have been found to be strong indicators of retention on teaching jobs and predictive of teachers' tendency to quit their jobs (e.g. McConnell, 2017; Skaalvik \& Skaalvik, 2011). 
Teacher job satisfaction according to Ainley and Carstens (2018) connotes "the sense of fulfilment and gratification that teachers experience through their work as a teacher"(p.43). It is a mixture of positive and negative evaluations teachers make about the teaching profession (Skaalvik \& Skaalvik, 2015). It is a multidimensional construct such that a teacher may make positive evaluations of one or more aspects of it and yet maintains negative evaluations of the others. Van der Ploeg and Scholte (2003) in (Veldman, van Tartwijk, Brekelmans, \& Wubbels, 2013) identified five dimensions of job satisfaction: "management support, autonomy, relations with colleagues, nature of work, and working conditions" (p.56). These dimensions are reduced to three in the construction of scales used in the current study. These three dimensions are (a) "teacher job satisfaction with work environment" (JSENV), (b) their "job satisfaction with profession" (JSPRO), and (c) their "job satisfaction with target class autonomy" (JSTCA), see OECD (2019b, p. 293).

The relations between teacher job satisfaction, and by extension its dimensions, with other constructs have been extensively studied in the literature. For example, Skaalvik and Skaalvik (2011) found that teachers with high job satisfaction exhibit low motivation to leave the profession $(\beta=-.53, p<.05)$, those with high sense of belonging exhibit high job satisfaction $(\beta=.28, p<.05)$ and teachers with high emotional exhaustion developed low job satisfaction $(\beta=-.53, p<.05)$. Similar corroborative findings have also been reported elsewhere (e.g. Skaalvik \& Skaalvik, 2015). A handful of empirical studies have also confirmed positive direct and interactive effects between teacher job satisfaction and school climate-related factors, e.g. teachers' collaboration in improving students' mathematics and reading growth as well learning outcomes (e.g. Banerjee, Stearns, Moller, \& Mickelson, 2016). In a more recent study, it is found that job satisfaction positively correlates with teachers' perceived school leadership styles and that this correlation is mediated by teacher professional collaboration (see García Torres, 2019). These findings suggest that the implications of high and/or low teacher job satisfaction are not only limited to teachers' well-being-related factors but also extend to students' learning outcomes, school organization and the community at large.

\section{Teacher self-efficacy}

The origin of self-efficacy, i.e. internal convictions to perform tasks with an estimation of desired outcomes, has been linked to the works of Albert Bandura. It is postulated to have four sources of influence: mastery experience, vicarious experience, verbal/social persuasions and physiological or affective states (Bandura, 1997; Zakariya, Goodchild, Bjørkestøl, \& Nilsen, 2019). It is an important affective factor that boosts job performance and a strong militating factor against attrition and absenteeism. Teacher self-efficacy according to Ainley and Carstens (2018) connotes 'the beliefs that teachers have of their ability to enact certain teaching behaviour that influences students' educational outcomes, such as achievement, interest, and motivation' (p. 51). The sources of self-efficacy as postulated by Bandura are recently investigated in a cross-national study among the Japanese and Finnish teachers. It was found that mastery experience has the strongest influence on the teachers' self-efficacy across the two countries (Yada et al., 2019). Therefore, from a theoretical perspective, teacher selfefficacy is a multifaceted affective construct. As such, three dimensions are conceptualized and operationalized to reflect teachers' self-efficacy by the TALIS 2018 team. These dimensions are: (a) "self-efficacy in classroom management" (TSECLS), (b) "self-efficacy in instruction" (TSEINS), and (c) "self-efficacy in student engagement" (TSEENG), see OECD (2019b, p. 275).

Several factors have been linked empirically to teacher self-efficacy in recent times. These include (a) factors that increase teacher self-efficacy, e.g. innovative teaching strategies and supportive school environment (Choi, Lee, \& Kim, 2019; Fackler \& Malmberg, 2016); (b) factors that decrease teacher self-efficacy, e.g. burnout and stress (Zhu et al., 2018); (c) factors that are positively affected by teacher self-efficacy, e.g. job satisfaction (Türkoğlu, Cansoy, \& Parlar, 2017). Teachers' job satisfaction appears to be the most widely studied factor in relation to teacher self-efficacy. A handful of studies have established a strong positive relation between teacher self-efficacy and job satisfaction with former enhancing the latter (e.g. Edinger \& Edinger, 2018; Skaalvik \& Skaalvik, 2014). A team of researchers in an empirical study involving 500 high school teachers using cluster analysis found that low burnout increases self-efficacy which in turn improves job satisfaction (Molero Jurado, Perez-Fuentes, Atria, Oropesa Ruiz, \& Gazquez Linares, 2019). These findings partly agree with an earlier study that confirmed a significant positive direct impact of teacher self-concept on self-efficacy and a significant negative direct impact of burnout on self-efficacy (Zhu et al., 2018). Thus, based on the aforementioned body of literature, it is hypothesized that:

(H01) Teachers' self-efficacy in classroom management, their self-efficacy in instruction and their selfefficacy in student engagement have direct positive effects on teachers' job satisfaction.

\section{School climate}

School climate which is sometimes referred to as school culture has consistently been identified to contribute significantly in sustaining school improvement, teachers' 
well-being and students' learning outcomes. A conducive and inclusive school climate that is free of hostility and bullying enhances teachers' job satisfaction, boosts selfefficacy, improves teacher-student relationship, reduces attrition and burnout (Lee \& Louis, 2019; Van Beurden, Van Veldhoven, Nijendijk, \& Van De Voorde, 2017). School climate is equally beneficial not only to the teachers but also to students' behaviour, approaches to learning, total well-being and improved achievement (Zakariya et al., 2019). According to Ainley and Carstens (2018), school climate is a multidimensional construct that encapsulates "safety, relationships, engagement with teaching and learning, institutional environment, and school improvement activities" (pp. 37-38). Thus, TALIS 2018 team conceptualized and operationalized three dimensions of this construct which are (a) "teachers' perceived disciplinary climate" (TPDC), (b) "teacher-student relations" (TSR), and (c) "participation among stakeholders" (TSTAKE), see OECD (2019b, p. 329).

There have been mixed results on the impacts of school climate on other constructs such as teacher selfefficacy and job satisfaction. These mixed results stemmed from different facets of the school climate. For example, it was found in a qualitative longitudinal study involving four highly job satisfied teachers that teacherstudent relationship is strongly positively related to teacher job satisfaction (Veldman et al., 2013). More so, teachers with high sense of belonging to the school system and have more opportunity to participate among stakeholders are reported to have high self-efficacy which translates to high job satisfaction (e.g. Skaalvik \& Skaalvik, 2011; You et al., 2016). On the other hand, teachers' perceived disciplinary climate has been reported to negatively impact self-efficacy which in turn translates to low job satisfaction (Aldridge \& Fraser, 2016; Malinen \& Savolainen, 2016). Building on this body of literature, the following hypotheses are formulated:

(H02) There is a direct positive effect of teacherstudent relations on job satisfaction.

(H03) There is a direct negative effect of teacher perceived disciplinary climate on job satisfaction.

(H04) The direct effects of each dimension of the school climate on job satisfaction are mediated by teacher self-efficacy.

(H05) The pattern of factor loadings, other estimated parameters, and regression coefficients are likely to be invariance across an independent sample.

Figure 1 explicitly demonstrates a graphical structural model of the hypothesized relations between the constructs of the current study. To the best of author's knowledge, no large-scale empirical study has ever been reported within Norway on the structural invariance of a model relating school climate, teacher self-efficacy and job satisfaction. The current study seeks to complement decades of research in understanding, identifying, recruiting, and retaining effective teachers.

The oval shapes in Fig. 1 depict the dimensions of each of the constructs: school climate, job satisfaction and teacher self-efficacy. Both JSTCA and TSTAKE are

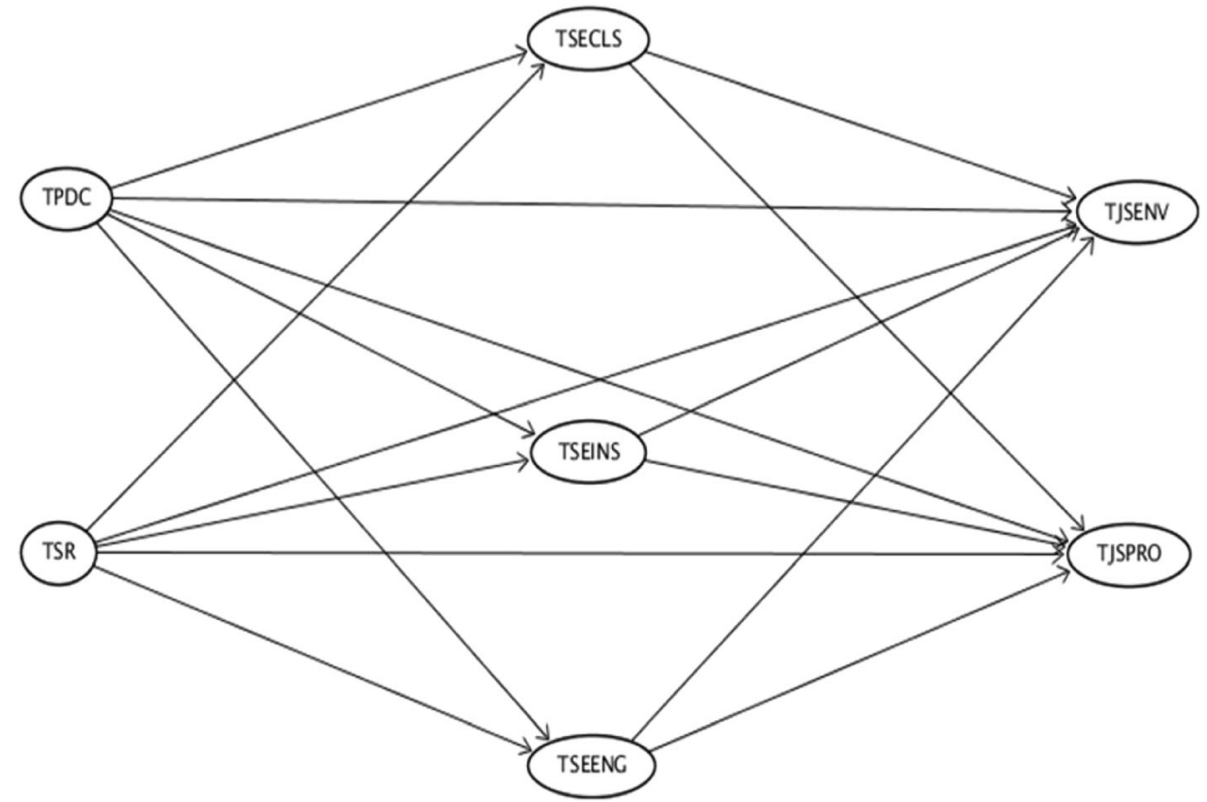

Fig. 1 A conceptual model of the relations between school climate (TPDC, teachers' perceived disciplinary climate and TSR, teacher-student relations ), job satisfaction (TJSENV, job satisfaction with work environment and TJSPRO, job satisfaction with profession), and teacher self-efficacy (TSECLS, self-efficacy in classroom management; TSEINS, self-efficacy in instruction; and TSEENG, self-efficacy in student engagement) 
not included in Fig. 1 because their corresponding data are not released by the TALIS 2018 team for lower secondary school teachers. The single-headed arrows indicate the direction of the theorized causal effects from one dimension of a construct to another. For instance, the single-headed arrow between TSECLS and TJSENV depicts a direct theorized casual effect of the 'teacher self-efficacy in classroom management' on the 'teacher job satisfaction with work environment' as hypothesized in H01. In the forthcoming section, data preparation, measures, procedure of analysis and other methodological related issues are presented.

\section{Methodology}

\section{Data preparation}

The data used for the current study came from the TALIS 2018 international survey. The survey took place towards the end of 2017/2018 academic year for teachers and principals in many countries across primary (ISCED 1), lower secondary (ISCED 2) and upper secondary schools (ISCED 3). Two hundred schools per country and 20 teachers in each school are sampled using probabilistic technique. In line with the aim of the current study, the ISCED 2 teacher data for Norway are extracted and teacher responses related to the variables of interest are prepared. ISCED 2 teacher data are used because no data are available for both ISCED 1 and ISCED 3 in Norway. These data are screened for outliers and 203 respondents out of a total of 4154 are found with missing values on all variables. These respondents are removed, and the effective data become 3951 including 2541 males (64.3\%) and 1410 females (35.7\%). The main source of the data used for the current study is publicly available on the OECD website (http://www.oecd.org/ education/).

\section{Measures}

Teacher job satisfaction is measured by TJSENV (four items) and TJSPRO (four items) subscales each measured on a four-point Likert scale ranges from 1 (strongly disagree) to 4 (strongly agree). Teacher selfefficacy is measured by TSECLS, TSEINS and TSEENG subscales each measured by four items on a four-point Likert scale ranges from 1 (not at all) to 4 (a lot). School climate is measured by TPDC (four items) and TSR (four items) subscales each measured on a four-point Likert scale ranges from 1 (strongly disagree) to 4 (strongly agree). All the subscales of the ISCED 2 teachers have high internal consistency with Omega reliability coefficients range from .706 to .901 and .642 on TSEENG subscale. They also exhibit measurement invariance up to metric level for Norwegian data (OECD, 2019b). Table 1 presents items measuring each subscale (including means and standard deviations for our sample, $N=3951$ ), their wordings and response options.

\section{Recoding and missing data}

It appears that items TG53C, TG53D, TG53F and TG41B are not reverse recorded to reflect their negatively worded nature before TALIS team made the 2018 data public. This is observed when these items show negative covariances with other subscale items in their respective constructs during data screening process. Thus, each of these items is recoded to reflect these changes. The data are screened for missing values using Little's missing completely at random (MCAR) tests. These tests show no significant statistics for each components of the teacher self-efficacy $\left(\chi^{2}=302.98, d f=317\right.$, $p=.750$ at $0.1-0.5 \%$ missing), borderline significant statistics for job satisfaction $\left(\chi^{2}=195.79, d f=165, p=.051\right.$ at $1.6-2.0 \%$ missing), and significant statistics for school climate $\left(x^{2}=134.25, d f=97, p=.007\right.$ at $1.0-14.2 \%$ missing). Thus, for convenient use of these data in subsequence analysis, full information maximum likelihood (FIML) estimation with expectation maximum (EM) algorithm is utilized as opposed to multiple imputation to replace the missing data (Cham, Reshetnyak, Rosenfeld, \& Breitbart, 2017).

\section{Data analysis procedure}

The extracted data are randomly split into two date sets using split at random command in SPSS version 23. The first data set (data 1) is made up of 1975 respondents (1300 males and 675 females) while the second data set (data 2) is made up of 1976 respondents (1241 males and 735 females). The data analyses proceed in two stages. Stage 1 involves using data 1 to calibrate measurement models for each of the constructs and to validate the structural model as well as to conduct post hoc analysis. Stage 2 involves using data 2 to cross-validate the established structural model in stage 1. Structural multigroup invariance techniques are adopted in stage 2 which involves comparing configural model models with more restrictive models. A combination of methods are used to access model fits in both stage 1 and stage 2 which includes: (a) significant parameter estimates; (b) goodness of fits (GOF) indices CFI, TLI close to or $\geq .95$, SRMR $\leq .08$ and RMSEA $\leq .06$; (c) chi-squared difference tests and changes in GOF indices, e.g. $\triangle \mathrm{CFI}>-.010$, $\triangle$ RMSEA $<.015$, and $\triangle$ SRMR $<.010$. These criteria are chosen because of their satisfactory performance reported in the literature (e.g. Chen, 2007; Hu \& Bentler, 1999). Considering the large sample size involved in the current study, chi-square statistic is not used to assess model fits because it has been deemed sensitive to sample size (Brown, 2015). Mplus version 8.3 software is 
Table 1 Item wordings, response options, means and standard deviations of each construct measuring teacher job satisfaction, selfefficacy and school climate of the study total sample $(N=3951)$

\begin{tabular}{|c|c|c|c|c|c|}
\hline Construct & Item & Item wording & Response options & Mean & Std. Dev. \\
\hline \multirow[t]{4}{*}{$\begin{array}{l}\text { TJSENV: Job satisfaction } \\
\text { with work environment }\end{array}$} & TG53C* & I would like to change to another school if that were possible & $\begin{array}{l}1 \text { (strongly disagree)- } \\
4 \text { (strongly agree) }\end{array}$ & 3.27 & .76 \\
\hline & TG53E & I enjoy working at this school & $\begin{array}{l}1 \text { (strongly disagree)- } \\
4 \text { (strongly agree) }\end{array}$ & 3.37 & 61 \\
\hline & TG53G & I would recommend this school as a good place to work & $\begin{array}{l}1 \text { (strongly disagree)- } \\
4 \text { (strongly agree) }\end{array}$ & 3.27 & 67 \\
\hline & TG53」 & All in all, I am satisfied with my job & $\begin{array}{l}1 \text { (strongly disagree)- } \\
4 \text { (strongly agree) }\end{array}$ & 3.18 & 68 \\
\hline \multirow[t]{4}{*}{$\begin{array}{l}\text { TJSPRO: Job satisfaction } \\
\text { with profession }\end{array}$} & TG53A & The advantages of being a teacher clearly outweigh the disadvantages & $\begin{array}{l}1 \text { (strongly disagree)- } \\
4 \text { (strongly agree) }\end{array}$ & 3.16 & 66 \\
\hline & TG53B & If I could decide again, I would still choose to work as a teacher & $\begin{array}{l}1 \text { (strongly disagree)- } \\
4 \text { (strongly agree) }\end{array}$ & 2.97 & .80 \\
\hline & TG53D* & I regret that I decided to become a teacher & $\begin{array}{l}1 \text { (strongly disagree)- } \\
4 \text { (strongly agree) }\end{array}$ & 3.39 & 69 \\
\hline & TG53F* & $\begin{array}{l}\text { I wonder whether it would have been better to choose another } \\
\text { profession }\end{array}$ & $\begin{array}{l}1 \text { (strongly disagree)- } \\
4 \text { (strongly agree) }\end{array}$ & 2.91 & .84 \\
\hline \multirow{4}{*}{$\begin{array}{l}\text { TSECLS: Self-efficacy in } \\
\text { classroom management }\end{array}$} & TG34D & Control disruptive behaviour in the classroom & 1 (not at all)-4 (a lot) & 3.00 & .64 \\
\hline & TG34F & Make my expectations about student behaviour clear & 1 (not at all)-4 (a lot) & 3.22 & 61 \\
\hline & $\mathrm{TG} 34 \mathrm{H}$ & Get students to follow classroom rules & 1 (not at all)-4 (a lot) & 3.05 & 60 \\
\hline & TG341 & Calm a student who is disruptive or noisy & 1 (not at all)-4 (a lot) & 3.01 & .64 \\
\hline \multirow{4}{*}{$\begin{array}{l}\text { TSEINS: Self-efficacy } \\
\text { in instruction }\end{array}$} & TG34C & Craft good questions for students & 1 (not at all)-4 (a lot) & 2.83 & .55 \\
\hline & TG34J & Use a variety of assessment strategies & 1 (not at all)-4 (a lot) & 2.91 & 69 \\
\hline & TG34K & $\begin{array}{l}\text { Provide an alternative explanation, for example when students are } \\
\text { confused }\end{array}$ & 1 (not at all)-4 (a lot) & 3.09 & 60 \\
\hline & TG34L & Vary instructional strategies in my classroom & 1 (not at all)-4 (a lot) & 2.85 & 68 \\
\hline \multirow{4}{*}{$\begin{array}{l}\text { TSEENG: Self-efficacy in } \\
\text { student engagement }\end{array}$} & TG34A & Get students to believe they can do well in school work. & 1 (not at all)-4 (a lot) & 2.88 & .58 \\
\hline & TG34B & Help students value learning & 1 (not at all)-4 (a lot) & 2.58 & 60 \\
\hline & TG34E & Motivate students who show low interest in school work. & 1 (not at all)-4 (a lot) & 2.34 & .57 \\
\hline & TG34G & Help students think critically & 1 (not at all)-4 (a lot) & 2.76 & 64 \\
\hline \multirow[t]{4}{*}{$\begin{array}{l}\text { TPDC: Teachers' perceived } \\
\text { disciplinary climate }\end{array}$} & TG41A & $\begin{array}{l}\text { When the lesson begins, I have to wait quite a long time for students } \\
\text { to quieten down }\end{array}$ & $\begin{array}{l}1 \text { (strongly disagree)- } \\
4 \text { (strongly agree) }\end{array}$ & 1.87 & .77 \\
\hline & TG41B* & $\begin{array}{l}\text { Students in this class take care to create a pleasant learning } \\
\text { atmosphere }\end{array}$ & $\begin{array}{l}1 \text { (strongly disagree)- } \\
4 \text { (strongly agree) }\end{array}$ & 2.22 & .74 \\
\hline & TG41C & I lose quite a lot of time because of students interrupting the lesson & $\begin{array}{l}1 \text { (strongly disagree)- } \\
4 \text { (strongly agree) }\end{array}$ & 2.03 & .79 \\
\hline & TG41D & There is much disruptive noise in this classroom & $\begin{array}{l}1 \text { (strongly disagree)- } \\
4 \text { (strongly agree) }\end{array}$ & 1.97 & .80 \\
\hline \multirow[t]{4}{*}{$\begin{array}{l}\text { TSR: Teacher-student } \\
\text { relations }\end{array}$} & TG49A & Teachers and students usually get on well with each other. & $\begin{array}{l}1 \text { (strongly disagree)- } \\
4 \text { (strongly agree) }\end{array}$ & 3.42 & .58 \\
\hline & TG49B & Most teachers believe that the students' well-being is important & $\begin{array}{l}1 \text { (strongly disagree)- } \\
4 \text { (strongly agree) }\end{array}$ & 3.69 & .47 \\
\hline & TG49C & Most teachers are interested in what students have to say. & $\begin{array}{l}1 \text { (strongly disagree)- } \\
4 \text { (strongly agree) }\end{array}$ & 3.44 & .54 \\
\hline & TG49D & If a student needs extra assistance, the school provides it. & $\begin{array}{l}1 \text { (strongly disagree)- } \\
4 \text { (strongly agree) }\end{array}$ & 3.12 & 64 \\
\hline
\end{tabular}


used for these analyses and the ensuing results are presented in next section.

\section{Results}

\section{Stage 1: Measurement models}

Three separate measurement models are analyzed using maximum likelihood with robust standard errors (MLR), one model for each of the variables: teacher job satisfaction, self-efficacy and school climate. MLR estimator was used as opposed to maximum likelihood and others because of its robustness to violations of multiple assumptions of normality distribution that are inherent in ordinal scales with less than 5-point categories (Suh, 2015). A good model fit $\left(\chi^{2}(17)=152.18, p<.001\right.$, RMSEA $=.063(90 \%$ C.I. $=0.054-0.073$, CFit $=.008)$, CFI $=.97$, TLI $=.94$, and SRMR $=.033$ ) was found for job satisfaction after accounting for an error covariance between TG53D and TG53F and a cross-loading of item TG53J on 'job satisfaction with profession' construct. The error cross-loading was suggested by the TALIS 20018 team in (OECD, 2019b) while the item crossloading was suggested by modification indices in the output of the analysis. The inclusion of this item crossloading gave a significant MLR chi-square difference test with Satorra-Bentler correction $\Delta \chi_{[1]}^{2}=171.50, p<.001$. From a conceptual point of view, item TG53J: All in all, I am satisfied with my job, seems to fit very well to measuring 'teacher job satisfaction with profession' rather than 'job satisfaction with work environment' as postulated by the TALIS team. Thus, from conceptual/ theoretical and statistical perspectives, inclusion of item cross-loading on 'job satisfaction with profession' construct in the measurement model appears to be duly justified.

The statistics of the analyzed measurement model for teacher self-efficacy variable also suggest a good model fit: $\chi^{2}(48)=330.76, p<.001$, RMSEA $=.055$ (90\% C.I. $=$ 0.049-0.060, CFit $=.082)$, CFI $=.95$, TLI $=.94$, and SRMR $=.037$. This model fit was achieved after accounting two error covariances between items TG34A with
TG34B and items TG34D with TG34I as recommended by the TALIS 2018 team (OECD, 2019b). Further, a good model fit $\left(\chi^{2}(19)=65.69, p<.001\right.$, RMSEA $=.035$ $(90 \%$ C.I. $=.026-.045$, CFit $=.995)$, CFI $=.99$, TLI $=.99$, and SRMR $=.026$ ) was found for the school climate variable. However, there was a negative significant standardized correlation $(r=-.18, p<.01)$ between 'teachers' perceived disciplinary climate' and 'teacher-student relations' constructs of the school climate. This has an implication for the impact of each of these constructs on other variables as it could be interpreted to mean those teachers with smooth student relations also have good perception of the disciplinary measures in their classrooms. All the estimated parameters, e.g. factor loadings, correlation coefficients, and factor variances, are significant. The validated measurement models were used in the structural model whose results are presented in the next section.

\section{Structural model}

Three structural models are evaluated in order to test hypothesis one (H01) to hypothesis four (H04). In model 1 , the structural direct effects of each dimension of teacher self-efficacy and job satisfaction are validated. On the other hand, model 2 establishes the direct effects of each dimension of school climate on job satisfaction while model 3 validates how these effects are mediated by each component of the teacher self-efficacy. Models 1 and 2 are found to demonstrate good fits with the following global fits statistics for model $1 ; \chi^{2}(155)=651.39$, $p<.001$, RMSEA $=.040$ (90\% C.I. $=0.037-0.043$, CFit $=$ $1.000)$, CFI $=.96$, TLI $=.95$, and SRMR $=.032$, and for model $2 ; \chi^{2}(96)=409.67, p<.001$, RMSEA $=.041(90 \%$ C.I. $=0.037-0.045$, CFit $=1.000)$, CFI $=.97$, TLI $=.96$, and SRMR $=.037$. Two non-significant structural paths are found in model 1 , and these are deleted before validating model 3. The global fit statistics for model 3 are $X^{2}(326)=1161.42, p<.001$, RMSEA $=.036$ (90\% C.I. $=$ 0.034-0.038, CFit $=1.000)$, CFI $=.96$, TLI $=.95$, and SRMR $=.036$. The unstandardized and the standardized

Table 2 Direct effects of each dimension of teacher self-efficacy and school climate variables on the two dimensions of job satisfaction

\begin{tabular}{|c|c|c|c|c|c|}
\hline \multirow[b]{2}{*}{ Construct path } & \multicolumn{2}{|c|}{ Model $1(N=1975)$} & \multirow[b]{2}{*}{ Construct path } & \multicolumn{2}{|c|}{ Model $2(N=1975)$} \\
\hline & $\overline{b(S . E .)}$ & $\beta$ & & $\overline{b(S . E .)}$ & $\beta$ \\
\hline TSECLS $\rightarrow$ TJSENV & $0.17^{*}(0.04)$ & $0.16^{*}$ & TPDC $\rightarrow$ TJSENV & $-0.11^{*}(0.03)$ & $-0.12^{*}$ \\
\hline TSECLS $\rightarrow$ TJSPRO & $0.00(0.05)$ & 0.00 & $\mathrm{TPDC} \rightarrow \mathrm{TJSPRO}$ & $-0.13^{*}(0.03)$ & $-0.13^{*}$ \\
\hline TSEINS $\rightarrow$ TJSENV & $0.34^{*}(0.18)$ & $0.10^{*}$ & TSR $\rightarrow$ TJSENV & $0.53^{*}(0.04)$ & $0.41^{*}$ \\
\hline TSEINS $\rightarrow$ TJSPRO & $0.42^{*}(0.20)$ & $0.11^{*}$ & TSR $\rightarrow$ TJSPRO & $0.32 *(0.04)$ & $0.23^{*}$ \\
\hline TSEENG $\rightarrow$ TJSENV & $-0.05(0.06)$ & -0.05 & & & \\
\hline TSEENG $\rightarrow$ TJSPRO & $0.14^{*}(0.07)$ & $0.11^{*}$ & & & \\
\hline
\end{tabular}

Note: The construct names are consistent with their meanings in Table 1. $\beta$ and b standardized and unstandardized regression weights, respectively, S.E. standard error and ${ }^{*} p<.05$ 


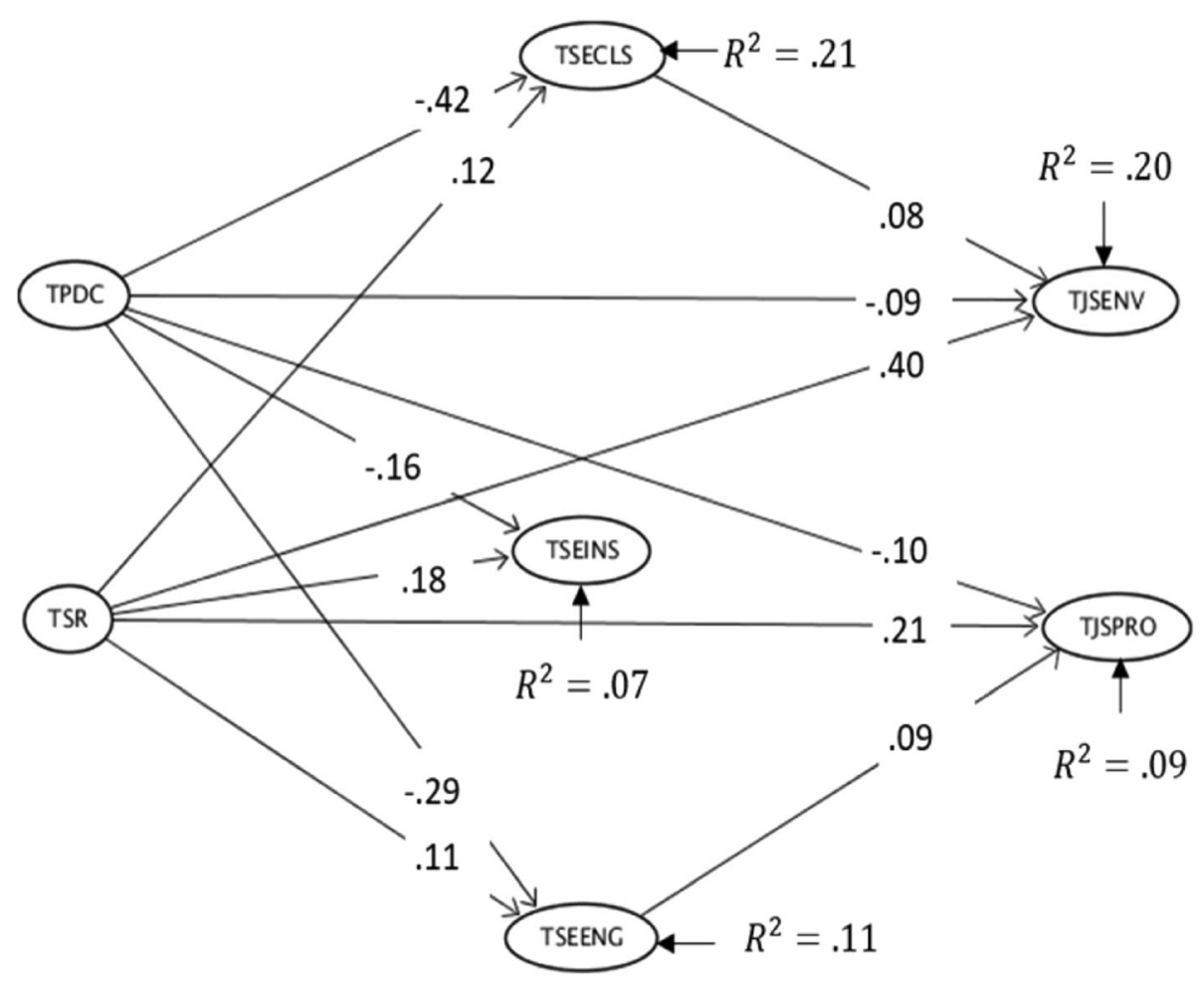

Fig. 2 A structural model of the effects of school climate (TPDC, teachers' perceived disciplinary climate and TSR, teacher-student relations) on job satisfaction (TJSENV, job satisfaction with work environment and TJSPRO, job satisfaction with profession) as mediated by the teacher selfefficacy (TSECLS, self-efficacy in classroom management; TSEINS, self-efficacy in instruction, and TSEENG, self-efficacy in student engagement). All parameter estimates are standardized and significant at $p<.05$

regression weights of each path for models 1 and 2 are presented in Table 2 while Fig. 2 displays only the standardized significant path weights and $R^{2}$ values of the predicted variables for model 3 .

The results in Table 2 (model 1) show that teachers' self-efficacy in classroom management and teachers' selfefficacy in instruction have significant direct effects on their job satisfaction with work environment while the direct of effect of the 'teachers' self-efficacy in student engagement' on their satisfaction with work environment is not significant. However, there is significant direct effect of teachers' self-efficacy in student engagement on their job satisfaction with profession. Also, the direct effect of teachers' self-efficacy in instruction on their job satisfaction with profession is significant while the direct effect of their 'self-efficacy in classroom management' is not significant. Further, among the three constructs that measure teacher self-efficacy it can be deduced that teachers' selfefficacy in instruction has the greatest effect on the overall job satisfaction of the teachers. This finding could be interpreted to mean that teachers who often craft good questions for students, use variety of assessment strategies and help confused students by giving alternative explanation are most probable of having high teaching job satisfaction in Norway. These results provide detail empirical evidence that confirms the first hypothesis (H01) of the current study.

The results presented in Table 2 (model 2) also reveal at a global level that school climate has significant direct impact on teachers' job satisfaction. Teacher-student relations appear to exert greater effect on teachers' job satisfaction than their perceived disciplinary climate which in parts confirm hypothesis two (H02). This finding could be interpreted to mean that schools whose teachers have good rapports with their students and care for students' well-being, are interested in the opinions of the students and provide extra assistance for students are more probable to have teachers with high job satisfaction. It is also confirmed, as postulated in hypothesis three (H03), that there is a significant negative effect of 'teachers' perceived disciplinary climate' on their job satisfaction. However, this negative effect needs to be interpreted with cautions going by the way the survey questions are framed. The finding confirms that schools whose teachers waste a lot of time getting students ready for lessons by managing disruptive noises, students' interruptions, and unpleasant atmosphere are more probable to have teachers with low job satisfaction.

The results presented Fig. 2 show at a global level that school climate have significant direct effects on teachers' 
self-efficacy in classroom management, instruction and student engagement. These can be deduced from the significant regression weights from each dimension of the school climate to the respective dimensions of teacher self-efficacy. It is found that $21 \%$ variance associated with 'teacher self-efficacy in classroom management', $11 \%$ variance associated with 'teacher self-efficacy in student engagement' and 7\% variance associated with 'teacher self-efficacy in instruction' are explained by the school climate-related factors. These percentages of explained variance appear low, however, they are statistically significant which could be indicative of the relevance of other predictor variables that are not accounted for in the current study. The results in Fig. 2 also generally confirm hypothesis four (H04) that teacher self-efficacy mediates the impact of school climate on teacher job satisfaction. This can be deduced from the absence of considerable changes in the standardized regression weights except that the direct impact of 'teacher self-efficacy in instruction' on 'job satisfaction with work environment' observed in Table 2 is no longer significant.

To further substantiate the mediating effect of teacher self-efficacy between the school climate and the teacher job satisfaction, a mediation analysis was conducted. The results show that 'teachers' perceived disciplinary climate' has a significant total effect of $-.128(p<.001)$ on 'job satisfaction with profession', a significant total effect of $-.106(p<.001)$ on 'job satisfaction with work environment', and significant total indirect effects of -.034 ( $p$ $<.001)$ and $-.030(p=.009)$ through teacher self- efficacy on 'job satisfaction with profession' and 'job satisfaction with work environment' respectively. It is also found that teacher-student relations have a significant total effect of .227 $(p<.001)$ on 'job satisfaction with profession', a significant total effect of $.405(p<.001)$ on 'job satisfaction with work environment', and a significant total indirect effect of $.020(p=.004)$ through teacher self-efficacy on job satisfaction with profession. However, the mediating effect of teacher self-efficacy between teacher-student relations and 'job satisfaction with work environment' is not significant $.010(p=.104)$. In summary, the results demonstrate evidence of mediating effect of the overall teacher self-efficacy construct between school climate and teacher job satisfaction. Further, $20 \%$ variance of 'teacher job satisfaction with work environment' and $9 \%$ variance associated 'job satisfaction with profession' are explained by the predictor variables.

\section{Stage 2: Cross-validation of the structural model}

In this section, results of the analyses on cross-validation of the structural model 3 established in stage 1 are presented. These analyses are in two steps. The first step involved fitting model 3 simultaneously on data 1 (calibration group, $N=1975$ ) and data 2 (validation group, $N=1976$ ) such that all parameters are freely estimated in the two groups. The second step involves multigroup invariance in which all factor loadings, regression weights and intercepts are constrained equal in the two groups. The results from the first (configural model) and second (constraints model) steps analyses are presented in Table 3.

Table 3 Selected GOF indices for structural measurement invariance across two samples

\begin{tabular}{|c|c|c|c|}
\hline & Configural model & Constraints model & Pchange \\
\hline \multicolumn{4}{|l|}{ Chi-square test of model fit } \\
\hline Value & 2258.913 & 2306.411 & 47.498 \\
\hline Degree of freedom & 652 & 711 & 59 \\
\hline$p$ value & $<.001$ & $<.001$ & - \\
\hline Scaling correction factor for MLR & 1.0902 & 1.0900 & - \\
\hline \multicolumn{4}{|c|}{ Chi-square contribution from each group } \\
\hline Calibration $(N=1975)$ & 1147.257 & 1170.915 & 23.658 \\
\hline Validation $(N=1976)$ & 1111.656 & 1135.496 & 23.840 \\
\hline \multicolumn{4}{|l|}{$\mathrm{CFI} / \mathrm{TLI}$} \\
\hline $\mathrm{CFI}$ & .956 & .956 & 0.000 \\
\hline $\mathrm{TLI}$ & .949 & .953 & .004 \\
\hline \multicolumn{4}{|c|}{ Root mean square error of approximation } \\
\hline RMSEA (90\% Cl) & $.035(.034-.037)$ & $.034(.032-.035)$ & .001 \\
\hline CFit & 1.000 & 1.000 & - \\
\hline \multicolumn{4}{|c|}{ Standardized root mean square residual } \\
\hline Value & .037 & .038 & .001 \\
\hline
\end{tabular}

Note. Pchange, change in goodness of indices across the configural and the constraints models. 
The results presented in Table 3 (configural model) reveal the extent to which the structural model 3 fits the data from both the calibration and the validation groups simultaneously with freely estimated parameters. There is a slight change between the chi-square values of the two groups (calibration $=1147.257$, validation = 1111.656, change $=35.601)$. However, the GOF indices indicated a good model fit of the two groups. This finding suggests that if the model parameters, e.g. factor loadings and regression weights, are allowed to freely estimate in both calibration and validation groups the overall model exhibit well-fitting statistics.

A review of the results in Table 3 (constraints model) confirms the extents to which factor loadings, intercepts and regression weights are invariance across the calibration and the validation groups. The results suggest a good fit of the model and demonstrate equality of constrained parameters across the two groups. This conclusion is evident from the non-significant MLR chisquare difference test with Satorra-Bentler correction $\Delta$ $X_{[59]}^{2}=47.179, p=.866$ coupled with slight or no changes in GOF indices that are within recommended values to establish measurement invariance (Chen, 2007). According to Meredith (1993) classification of multigroup invariance model, these results could be interpreted to be indicative of strong measurement and structural invariance which confirm hypothesis five (H05) of the current study.

\section{Discussion}

An understanding of the relations between school climate, teachers' self-efficacy and their job satisfaction has a vital role to play in identifying, recruiting and retention of teachers. This is important for improving teachers' well-being, quality of school management, teaching and learning outcomes. However, previous studies on these relations are either led to inconclusive findings or lack cross-validation of the established models. Thus, findings of the current study provide empirical evidence for a cross-validated structural model that explains the direct/ indirect effects of school climate and teacher selfefficacy on job satisfaction. This model is also found to be invariance in estimated parameters, e.g. factor loadings, regression weights and intercepts, across two independent samples from a population.

In specific terms, it was found that 'teachers' selfefficacy in classroom management', their self-efficacy in instruction and their self-efficacy in student engagement have direct effects on teaching job satisfaction. The effect of 'teachers' self-efficacy in instruction' on job satisfaction appeared to be the greatest among the three dimensions of the teacher self-efficacy. These findings are consistent in parts with the results reported in
(Edinger \& Edinger, 2018; Skaalvik \& Skaalvik, 2014). However, the dimensions of teachers' self-efficacy used in those two studies are slightly different from that of the current study. Nonetheless, the findings of the current study corroborate the two previously reported and seem to contradict that of Shaukat et al. (2019) who reported no significant relationship between teacher selfefficacy and job satisfaction. This disparity between the findings of the current study and that of Shaukat et al. (2019) could be linked to either small sample size $(N=$ 118 ) involved in their study or some methodological issues (e.g. no account for measurement errors in predictor variables) inherent in the use of analysis of variance (ANOVA).

Another important finding that is revealed in the current study is the direct effect of school climate on teachers' job satisfaction. Both the teacher-student relations and the 'teachers' perceived disciplinary climate' have strong relations with the two dimensions of job satisfaction. That is, schools with conducive environment that is free of disruptive noises and unruly student behaviour, whose teachers have good rapports with their students and care for students' well-being, are interested in the opinions of the students and provide extra assistance for students, are more probable to have teachers with high job satisfaction. Consistent with the findings of Veldman et al. (2013), it is confirmed in the current study that teacher-student relations exert greater effect on job satisfaction than the other dimension of school climate variable. These findings in parts also corroborate the report of strong relations between school climate/ culture and teacher job satisfaction reported in You et al. (2016).

Further, It is found that 'teachers perceived disciplinary climate' has negative effect on job satisfaction just as it was reported in Aldridge \& Fraser (2016) and Malinen \& Savolainen (2016). However, this negative effect needs to be interpreted with cautions going by the way the survey questions are framed as mentioned before. In fact, the negative effects are positive conceptually because the questionnaire requires the teachers to rate the level of their agreement from 1 (strongly disagree) to 4 (strongly agree) with negatively worded statements, see Table 1. Thus, these findings revealed that schools whose teachers waste a lot of time getting students ready for lessons by managing disruptive noises, students' interruptions and unpleasant atmosphere are more probable to have teachers with low job satisfaction with work environment and profession.

The global effect of school climate on teacher job satisfaction is mediated by teacher self-efficacy. However, empirical evidence is only provided for strong indirect effects of teacher-student relation on 'job satisfaction with profession' through 'self-efficacy in student engagement' and 
strong indirect effect of 'teacher perceived disciplinary climate' on 'job satisfaction with work environment' through 'self-efficacy in classroom management'. These findings are consistent with the results of most studies on the relations between these constructs (e.g. Aldridge \& Fraser, 2016; Malinen \& Savolainen, 2016). Finally, a relatively unique finding of this study is the invariance of the model that explains the relations between school climate, teacher self-efficacy and job satisfaction. This model was found to be invariant in factor loadings, intercepts, and regression weights across two independent samples from the same population. It could be interpreted to be evidence of cross-validation that enhance the possibility of getting similar results when the study is replicated. Some limitations of this study are briefly discussed in the next section.

\section{Limitations of the study}

There are a number of limitations to the current study. The first limitation concerns the unavailability of the response data that capture 'teacher job satisfaction with target class autonomy' and 'participation among stakeholders' that measure dimensions of job satisfaction and school climate respectively. These data are not included in the public data provided by TALIS 2018 team. Perhaps, the availability of these data would have improved the model results especially the explained variance of the job satisfaction and the teacher self-efficacy that appear low. Another limitation concerns non-feasibility of cross validating the established model of this study across other educational levels, e.g. primary and upper secondary school levels. This would have increased the generalization of the results to a wider range of teachers. However, this is not possible because no national data are available for these levels. Further, it is acknowledged that a threat to the external validity of the findings of the current study could stem from the restriction of the study sample to a Scandinavian country. Perhaps, more refine findings could have been discovered if crosscountry analyses are investigated.

\section{Conclusions}

The findings reported in this article have provided empirical evidence for the structural relations between school climate, teacher self-efficacy and job satisfaction. Proper understanding of this relationship is very crucial in identification, recruitment and sustainability of effective teachers. The school climate factors are found to have direct effect on teacher job satisfaction. However, this direct effect is mediated by some dimensions of teacher selfefficacy. A strength of these findings lies in the large sample involved coupled with the robust structural equation modeling approach used unlike mere correlational studies in the literature (e.g. Hosford \& O'Sullivan, 2016; Shaukat et al., 2019). Another important contribution of this study to the literature is the cross-validation of the established structural model using independent sample from the same population. This type of structural model cross-validation technique is very important for generalization of results, and it is rarely reported in the literature (Byrne, 2012), perhaps for the obvious reason of lack of enough sample to conduct the analysis.

This section is concluded by making two important observations on the general use of TALIS 2018 data for future studies. The first observation concerns the recoding of items TG53C, TG53D, TG53F and TG41B to reflect their negatively worded nature. TALIS 2018 team mentioned in their technical report that these items were reversed coded during the scale constructions and validations. However, what seems apparent is that responses on these items are not reversed coded in the 2018 survey data released to the public. This conclusion is reached because of the negative covariances found between these items and other items in their respective constructs during data screening process. The second observation concerns cross-loading of the item TG53): All in all, I am satisfied with my job (that was hypothesized to measure 'job satisfaction with work environment') onto 'job satisfaction with profession' construct. This cross-loading is found to significantly improve parsimony and goodness of fits indices of the measurement model when included. It is therefore recommended for researchers who will be using TALIS 2018 data to take note of these observations.

\section{Acknowledgments \\ The author acknowledges the support received from the University of Agder library for funding the article processing charge. \\ Authors' contributions \\ YF designed the research, pooled the data from TALIS 2018 public archive, conducted the analyses, and wrote the manuscript. YF read and approved the final manuscript. \\ Funding \\ No funding to declare.}

Availability of data and materials

The data used for the current study are available upon request from the corresponding author.

\section{Competing interests}

The author declares no competing interest.

Received: 8 November 2019 Accepted: 20 February 2020

Published online: 09 March 2020

\footnotetext{
References

Ainley, J., \& Carstens, R. (2018). Teaching and Learning International Survey (TALIS) 2018 conceptual framework, OECD working papers, No. 187. Paris: OECD Publishing.

Aldridge, J. M., \& Fraser, B. J. (2016). Teachers' views of their school climate and its relationship with teacher self-efficacy and job satisfaction. Learning Environments Research, 19(2), 291-307. https://doi.org/10.1007/s10984-0159198-x.

Bandura, A. (1997). Self-efficacy: the exercise of control. New York: W. H. Freeman and Company.
} 
Banerjee, N., Stearns, E., Moller, S., \& Mickelson, R. A. (2016). Teacher job satisfaction and student achievement: the roles of teacher professional community and teacher collaboration in schools. American Journal of Education, 123(2).

Blackburn, J. J., \& Robinson, J. S. (2008). Assessing teacher self-efficacy and job satisfaction of early career agriculture teachers in Kentucky. Journal of Agricultural Education, 49(3), 1-11.

Bronfenbrenner, U. (1986). Ecology of the family as a context for human development: research perspectives. Developmental Psychology, 22(6). https:// doi.org/10.1037/0012-1649.22.6.723.

Brown, T. A. (2015). Confirmatory factor analysis for applied research. New York, London: The Guilford Press.

Byrne, B. M. (2012). Structural equation modeling with Mplus: basic concepts, applications, and programming. New York: Routledge, Taylor \& Francis Group.

Caprara, G. V., Barbaranelli, C., Steca, P., \& Malone, P. S. (2006). Teachers' selfefficacy beliefs as determinants of job satisfaction and students' academic achievement: a study at the school level. Journal of School Psychology, 44(6), 473-490. https://doi.org/10.1016/j.jsp.2006.09.001.

Cham, H., Reshetnyak, E., Rosenfeld, B., \& Breitbart, W. (2017). Full information maximum likelihood estimation for latent variable interactions with incomplete indicators. Multivariate Behavioral Research, 52(1), 12-30. https:// doi.org/10.1080/00273171.2016.1245600.

Chen, F. F. (2007). Sensitivity of goodness of fit indexes to lack of measurement invariance. Structural Equation Modeling: A Multidisciplinary Journal, 14(3), 464-504. https://doi.org/10.1080/10705510701301834.

Choi, J., Lee, J.-H., \& Kim, B. (2019). How does learner-centered education affect teacher self-efficacy? The case of project-based learning in Korea. Teaching and Teacher Education, 85, 45-57. https://doi.org/10.1016/j.tate.2019.05.005.

Darling, N. (2007). Ecological systems theory: the person in the center of the circles. Research in Human Development, 4(3-4), 203-217. https://doi.org/10. 1080/15427600701663023

Edinger, S. K., \& Edinger, M. J. (2018). Improving teacher job satisfaction: the roles of social capital, teacher efficacy, and support. The Journal of Psychology, 152(8), 573-593. https://doi.org/10.1080/00223980.2018.1489364.

Fackler, S., \& Malmberg, L.-E. (2016). Teachers' self-efficacy in 14 OECD countries: teacher, student group, school and leadership effects. Teaching and Teacher Education, 56, 185-195. https://doi.org/10.1016/j.tate.2016.03.002.

García Torres, D. (2019). Distributed leadership, professional collaboration, and teachers' job satisfaction in U.S. schools. Teaching and Teacher Education, 79, 111-123. https://doi.org/10.1016/j.tate.2018.12.001.

Hosford, S., \& O'Sullivan, S. (2016). A climate for self-efficacy: the relationship between school climate and teacher efficacy for inclusion. International Journal of Inclusive Education, 20(6), 604-621. https://doi.org/10.1080/ 13603116.2015.1102339.

Hu, L. t., \& Bentler, P. M. (1999). Cutoff criteria for fit indexes in covariance structure analysis: conventional criteria versus new alternatives. Structural Equation Modeling: A Multidisciplinary Journal, 6(1), 1-55. https://doi.org/10. 1080/10705519909540118.

Lee, M., \& Louis, K. S. (2019). Mapping a strong school culture and linking it to sustainable school improvement. Teaching and Teacher Education, 81, 84-96. https://doi.org/10.1016/j.tate.2019.02.001.

Malinen, O.-P., \& Savolainen, H. (2016). The effect of perceived school climate and teacher efficacy in behavior management on job satisfaction and burnout: a longitudinal study. Teaching and Teacher Education, 60, 144-152. https://doi. org/10.1016/j.tate.2016.08.012.

McConnell, J. R. (2017). A model for understanding teachers' intentions to remain in STEM education. International Journal of STEM Education, 4(1), 7. https:// doi.org/10.1186/s40594-017-0061-8.

Meredith, W. (1993). Measurement invariance, factor analysis and factorial invariance. Psychometrika, 58(4), 525-543. https://doi.org/10.1007/BF02294825.

Molero Jurado, M. D. M., Perez-Fuentes, M. D. C., Atria, L., Oropesa Ruiz, N. F., \& Gazquez Linares, J. J. (2019). Burnout, perceived efficacy, and job satisfaction: perception of the educational context in high school teachers. BioMed Research International, 2019, 1021408. https://doi.org/10.1155/2019/1021408.

OECD. (2014). TALIS 2013 results: an international perspective on teaching and learning. Paris: TALIS, OECD Publishing.

OECD. (2019a). TALIS 2018 results (volume I): teachers and school leaders as lifelong learners. Paris: TALIS, OECD Publishing.

OECD. (2019b). TALIS 2018 technical report. Paris: TALIS, OECD Publishing.

Shaukat, S., Vishnumolakala, V. R., \& Al Bustami, G. (2019). The impact of teachers' characteristics on their self-efficacy and job satisfaction: a perspective from teachers engaging students with disabilities. Journal of Research in Specia Educational Needs, 19(1), 68-76. https://doi.org/10.1111/1471-3802.12425.

Skaalvik, E. M., \& Skaalvik, S. (2011). Teacher job satisfaction and motivation to leave the teaching profession: Relations with school context, feeling of belonging, and emotional exhaustion. Teaching and Teacher Education, 27(6), 1029-1038. https://doi.org/10.1016/j.tate.2011.04.001.

Skaalvik, E. M., \& Skaalvik, S. (2014). Teacher self-efficacy and perceived autonomy: relations with teacher engagement, job satisfaction, and emotional exhaustion. Psychological Reports, 114(1), 68-77. https://doi.org/10.2466/14.02. PR0.114k14w0.

Skaalvik, E. M., \& Skaalvik, S. (2015). Job satisfaction, stress and coping strategies in the teaching pofession-what do teachers say? International Education Studies, 8(3). https://doi.org/10.5539/ies.v8n3p181.

Suh, Y. (2015). The performance of maximum likelihood and weighted least square mean and variance adjusted estimators in testing differential item functioning with nonnormal trait distributions. Structural Equation Modeling: A Multidisciplinary Journal, 22(4), 568-580. https://doi.org/10.1080/10705511. 2014.937669

Türkoğlu, M. E., Cansoy, R., \& Parlar, H. (2017). Examining relationship between teachers' self-efficacy and job satisfaction. Universal Journal of Educational Research, 5(5), 765-772. https://doi.org/10.13189/ujer.2017.050509.

Van Beurden, J., Van Veldhoven, M., Nijendijk, K., \& Van De Voorde, K. (2017). Teachers' remaining career opportunities: the role of value fit and school climate. Teaching and Teacher Education, 68, 143-150. https://doi.org/10. 1016/j.tate.2017.09.002.

Veldman, I., van Tartwijk, J., Brekelmans, M., \& Wubbels, T. (2013). Job satisfaction and teacher-student relationships across the teaching career: four case studies. Teaching and Teacher Education, 32, 55-65. https://doi.org/10.1016/j. tate.2013.01.005

Yada, A., Tolvanen, A., Malinen, O.-P., Imai-Matsumura, K., Shimada, H., Koike, R., \& Savolainen, H. (2019). Teachers' self-efficacy and the sources of efficacy: a cross-cultural investigation in Japan and Finland. Teaching and Teacher Education, 81, 13-24. https://doi.org/10.1016/j.tate.2019.01.014.

You, S., Kim, A. Y., \& Lim, S. A. (2016). Job satisfaction among secondary teachers in Korea: effects of teachers' sense of efficacy and school culture. Educational Management Administration \& Leadership, 45(2), 284-297. https://doi.org/10. $1177 / 1741143215587311$

Zakariya, Y. F., Goodchild, S., Bjørkestøl, K., \& Nilsen, H. K. (2019). Calculus selfefficacy inventory: Its development and relationship with approaches to learning. Education Sciences, 9(3), 170. https://doi.org/10.3390/ educsci9030170.

Zhu, M., Liu, Q., Fu, Y., Yang, T., Zhang, X., \& Shi, J. (2018). The relationship between teacher self-concept, teacher efficacy and burnout. Teachers and Teaching, 24(7), 788-801. https://doi.org/10.1080/13540602.2018.1483913.

\section{Publisher's Note}

Springer Nature remains neutral with regard to jurisdictional claims in published maps and institutional affiliations.

\section{Submit your manuscript to a SpringerOpen ${ }^{\circ}$ journal and benefit from:}

- Convenient online submission

- Rigorous peer review

- Open access: articles freely available online

High visibility within the field

- Retaining the copyright to your article

Submit your next manuscript at $>$ springeropen.com 